\title{
Individual Baseline Balance Assessments in a Large Sample of Incoming NCAA Division I Athletes Using a Force Plate System
}

\author{
Scott A. Weismiller, DO, MS ${ }^{1}$, Robert Monaco, MD, MPH${ }^{2}$, Jason Womack, MD³, Brandon Alderman, $\mathrm{PhD}^{4}$, Carrie \\ Esopenko, PhD ${ }^{5}$, Fiona N. Conway, PhD ${ }^{6}$, Kyle Brostrand, MS, ATC , Allison Brown, PT, PhD ${ }^{5}$, Nicola L. de Souza, MSc ${ }^{8}$ \\ Jennifer F. Buckman, $\mathrm{PhD}^{4}$ a \\ 1 Dept. of Internal Medicine, Penn State Health, Milton S. Hersey Medical Center, ${ }^{2}$ Atlantic Sports Health, ${ }^{3}$ Dept. of Family Medicine \& Community \\ Health, Rutgers - Robert Wood Johnson Medical School; Dept. of Athletics, Rutgers University - New Brunswick, ${ }^{4}$ Dept. of Kinesiology and Health, \\ Rutgers University - New Brunswick, ${ }^{5}$ Dept. of Rehabilitation and Movement Sciences, Rutgers Biomedical and Health Sciences, ${ }^{6}$ Steve Hicks School \\ of Social Work, The University of Texas at Austin, ${ }^{7}$ Dept. of Athletics, Rutgers University - New Brunswick; Robert Wood Johnson Barnabas Health - \\ Rutgers Sports Medicine, 8 School of Graduate Studies, Rutgers Biomedical and Health Sciences \\ Keywords: sex differences, postural control, normative data, concussion, college
}

https://doi.org/10.26603/001c.18713

\section{International Journal of Sports Physical Therapy}

Vol. 16, Issue 1, 2021

\section{BACKGROUND}

Individualized baseline testing is resource and time intensive. The use of normative data to approximate changes after a suspected concussion is thus an appealing alternative. Yet, few peer-reviewed, large-sample studies are available from which to develop accurate normative averages of balance using force-plate technology.

\section{PURPOSE}

This study sought to validate a normative dataset from the force-plate manufacturer and examine the magnitude and nature of sample variability.

\section{STUDY DESIGN}

Cross-sectional.

\section{METHODS}

Baseline balance and self-reported sex, sport, and concussion history were assessed in 533 prospective collegiate athletes (45\% female) during pre-participation physical examinations. Balance was measured using four stances from the modified Clinical Test of Sensory Interaction and Balance and quantified as Sway Index Scores with the Biodex Biosway Portable Balance System. Group averages are contrasted to data from the force-plate manufacturer. Individual variability around these averages was visualized and analyzed by sex and sport.

\section{RESULTS}

Male student athletes showed significantly more sway in the eyes open, soft stance condition than female athletes. These differences were maintained when concussion history was included as a covariate. Athletes, particularly male athletes, in the high versus low contact sport group showed significantly more sway in the eyes open, soft surface and the eyes closed, hard and soft surface stances.

\section{CONCLUSION}

There was substantial individual variability that was partially explained by sex differences and sport differences. The development of normative averages for sway may benefit from

Please address all correspondence to: Jennifer Buckman, $\mathrm{PhD}$

Rutgers University-New Brunswick 607 Allison Road, Piscataway, NJ 08854 Email: jbuckman@rutgers.edu Phone: 848-445-0793; Fax: 732-445-3500 
consideration of sex and sport. Further studies should characterize other factors that influence baseline balance in collegiate athletes.

\section{LEVEL OF EVIDENCE}

$2 \mathrm{~b}$

\section{INTRODUCTION}

Balance, or postural control, is an integral clinical measure in the comprehensive diagnosis and management of sportrelated concussion. ${ }^{1}$ According to the most recent consensus statement from the fifth international conference on concussion in sport, ${ }^{2}$ balance disturbances are a clear onthe-field sign of a concussion. Assessments of postural control after a concussion often highlight transient deficits in an individual's ability to integrate the sensory components necessary for maintaining balance. ${ }^{3,4}$ Sensory integration and balance deficits have been reported among concussed athletes, ${ }^{5-7}$ and collectively suggest that brain regions responsible for coordinating sensory and vestibular modalities may be disrupted following sport-related concussion. ${ }^{8}$

Making accurate evaluations of balance disturbances post-injury may be compromised without an accurate preinjury comparison. ${ }^{4}$ Normative averages (i.e., norms) are commonly used in place of individualized baseline testing for characterizing changes in balance after a suspected concussion. This is due to the time and expense of individuallevel testing, perceptions of baseline testing inaccuracy, and clinical practice guides ${ }^{2}$ that suggest that baseline testing for other clinical measures (e.g., neuropsychological testing) may be "useful", but not mandatory. However, to be effective, norms must be developed on large, representative samples and consider factors that systematically influence them.

The present study assessed balance in a large sample of incoming NCAA Division I collegiate student-athletes. The Modified Clinical Test of Sensory Interaction and Balance (mCTSIB) combined with force plate technology was used as a sensitive and objective test of postural control. ${ }^{8}$ The fourstance mCTSIB was developed to assess the influence of somatosensory, visual, and vestibular systems on postural control. ${ }^{9}$ Its clinical and research utility comes from its relative ease of use and minimal cost. ${ }^{10}$ Combined with a force plate system, uniform, quantitative assessments of balance were obtained. The goals of the study were to validate the normative data previously published by the manufacturer of the balance system that was employed ${ }^{11}$ and examine the magnitude and nature of sample variability. Sample variability related to sex differences was hypothesized as female athletes have been shown to demonstrate superior balance compared to male athletes. ${ }^{12-15}$ Sample variability based on participation in high versus low contact sports was also hypothesized because of potential long-term cognitive effects of high contact risk sport participation. ${ }^{16}$ Finally, due to that possibility that individuals with a history of concussion may exhibit sustained balance disturbances compared with individuals without a history of concussion, ${ }^{17}$ self-reported concussion was controlled for in all analyses.

\section{METHODS}

\section{PARTICIPANTS}

Incoming NCAA Division I collegiate student-athletes between the ages of 18 and 23 years $(n=703)$ from 22 Division I teams at a northeastern US university were recruited when they attended their standard pre-participation physicals that took place before entry into the athletic program (2013 - 2016). On the day of recruitment, participants completed athletic program paperwork, research surveys, and a medical check-up; some participants also opted to participate in a separate study on heart rate variability that involved no physical activity.

Consented participant data were included if the athlete received a balance test using force plate technology in the Department of Sports Medicine, were active and uninjured members of an NCAA team at the time of testing, and received medical clearance for athletic participation $(n=534)$. Data from one individual were excluded due to baseline values that exceeded realistic expectations of a normal baseline test (i.e., > 3 standard deviations from next highest score). The final sample for analyses included 533 studentathletes (18.7+/- 1.0 years; $45 \%$ female). All participants provided written informed consent and this study was approved by the university's institutional review board. The study design was cross-sectional in nature.

\section{BALANCE ASSESSMENT}

Balance during the mCTSIB stances was objectively measured using the Biodex BioSway Portable Balance System (Biodex Medical Systems, Shirley NY), a force plate technology that evaluates balance as center of pressure (COP) trajectories, postural sway, and the ability to distribute and maintain one's center of gravity over the base of support. ${ }^{18}$ Participants alternated between standing on a high-density foam pad or a firm surface, in both the eyes open and eyes closed positions. ${ }^{9,18}$ Participants completed four 20-second stances from the mCTSIB: standing on a firm surface with eyes open (Open/Firm), standing on a firm surface with eyes closed (Closed/Firm), standing on a compliant surface (foam) with eyes open (Open/Soft) and standing on a foam surface with eyes closed (Closed/Soft). Participants were asked to stand quietly and motionless in the upright position during each condition. Sway information was collected by positioning the patient centrally on the static force plate and recording movement from center as X,Y coordinates. The Sway Index, calculated by the Biosway system, is the root mean squared difference of the $\mathrm{X}, \mathrm{Y}$ coordinates. ${ }^{11}$ Higher Sway Index scores are indicative of a more unsteady posture. All assessments were administered in the university's sports medicine office suite by medical staff, athletic trainers, study investigators, or trained graduate-level research assistants and took less than 5 minutes per athlete. 


\section{SEX, SPORT TYPE, AND CONCUSSION HISTORY}

Sex (male/female) and sport were collected from pre-participation questionnaires routinely administered by the Department of Sports Medicine to incoming athletes. A twocategory sport contact risk level variable was created based on the relative risk of sustaining an acute injury by sport using classification recommendations by the Council of Sports Medicine and Fitness. ${ }^{19}$ The high contact risk sport category included sports with purposeful and forceful collision with persons or objects (football, lacrosse, wrestling) or routine but lower impact contact (basketball, field hockey, gymnastics, soccer). The low contact risk category included sports with minimal and unintentional contact (baseball, softball, volleyball) or rare to no contact (crew, golf, swimming/diving, track and field, tennis). Diving was considered a contact sport in a prior study; ${ }^{19}$ however, the university from which the present sample was recruited has a combined swimming/diving team, which historically has had few concussions; therefore, the team was considered low contact. Self-reported history of concussion (yes/no) was determined from the pre-participation physical questionnaire item ("Have you ever had a head injury or concussion?”) and from supplementary physician notes.

\section{STATISTICAL METHODS}

The BioSway Portable System allows testers to record whether a test was performed at baseline or post-injury. If baseline assessments were recorded on multiple days (e.g., due to participation in other studies), only the first day's measurement was included to reduce potential of practice effects. If two baseline assessments were recorded within five min of each other (e.g., due to incomplete first recording, technical or computer error), only the second measurement was included.

All analyses were performed separately for the four stances (Open/Soft, Closed/Soft, Open/Firm, Closed/Firm). First, Sway Index scores per stance in the present sample were compared to those reported by the force-plate manufacturer for 17-23 year old male and female NCAA athletes $(\mathrm{n}=480)^{11}$ using Cohen's $d$ effect size calculations. ${ }^{20}$ Due to unequal variances in the two samples, Cohen's $d$ was computed using a pooled standard deviation term. Cohen's $d$ 's of $>0.2,>0.5$, and $>0.8$ are respectively considered small, medium and large effects.

Second, Sway Index scores in the present sample were graphically depicted by individual for each of the four stances. This was done to provide a qualitative assessment of balance differences between individuals. Graphs show overall sample variability.

Third, statistical analyses assessed whether sex differences or contact risk level differences accounted for the observed balance differences between individuals. A series of t-tests (SAS 9.4, SAS Institute Inc., Cary, NC) compared Sway Index scores across biological sex (male/female). A second series of $t$-tests compared Sway Index scores across contact risk level (high versus low contact). Analyses were performed again as general linear models (SAS 9.4, SAS Institute Inc., Cary, NC) that included self-reported concussion history as a covariate.
Table 1: Athletes Sex, Self-reported Concussion History, and Sport in the Low and High Contact Risk Groups

\begin{tabular}{|c|c|c|}
\hline & $\begin{array}{c}\text { Low Contact }(n= \\
228,43 \%)\end{array}$ & $\begin{array}{c}\text { High Contact ( } \mathrm{n}= \\
305,57 \%)\end{array}$ \\
\hline$\%$ Male & $40 \%$ & $66 \%$ \\
\hline $\begin{array}{l}\text { Concussion } \\
\text { history }\end{array}$ & $12 \%$ & $23 \%$ \\
\hline $\begin{array}{l}\text { Sport (\% } \\
\text { male) }\end{array}$ & $\begin{array}{l}\text { Baseball (100\%) } \\
\text { Crew (0\%) } \\
\text { Golf (50\%) } \\
\text { Softball (0\%) } \\
\text { Swim/Diving (0\%) } \\
\text { Track/Field (59\%) } \\
\text { Tennis (0\%) } \\
\text { Volleyball (0\%) }\end{array}$ & $\begin{array}{l}\text { Basketball (50\%) } \\
\text { Field Hockey (0\%) } \\
\text { Football }(100 \%) \\
\text { Gymnastics }(0 \%) \\
\text { Lacrosse }(65 \%) \\
\text { Soccer }(46 \%) \\
\text { Wrestling (100\%) }\end{array}$ \\
\hline
\end{tabular}

Finally, a chi-square test (SAS 9.4, SAS Institute Inc., Cary, NC) compared whether male and female athletes differ in their participation in high and low contact risk sports. Because there were significant differences by sex, a final set of $t$-tests assessed the effect of contact risk level on Sway Index scores separately for males and females. Differences were considered significant when $p<.05$.

\section{RESULTS}

Distribution of the current sample by sex and sport contact risk level is shown in Table 1. Differences between the sample averages published by the manufacturer of the force plate system (Biodex) and the present sample are shown in Table 2. There were negligible differences in the Closed/ Firm stance, small effect size differences in Open/Firm and Closed/Soft stances, and a moderate difference in the Open/ Soft stance. The present sample had smaller standard deviations than the previously published dataset in all but the Closed/Soft stance.

Individual-level Sway Index scores for each stance are presented in Figure 1. This figure graphically illustrates the range in individual Sway Index scores around sample averages. Independent sample $t$-tests were then performed to assess whether this variability was due to differences in sex and risk of contact. As shown in Table 2, male student-athletes exhibited more sway than female student-athletes in the Open/Soft, $t_{531}=2.69, p=.007$, but not in the Closed/ Soft, $t_{531}=1.87, p=.061$, stances, Open/Firm, $t_{531}=1.55, p$ $=.122$, or Closed/Firm, $t_{531}=1.62, p=.105$, stances $($ Table 2). Athletes in high versus low contact risk sports showed significant more sway in the Closed/Firm, $t_{531}=2.18, p=$ 0.03, Open/Soft, $t_{531}=2.47, p=0.014$, and Closed/Soft, $t_{531}$ $=2.48, p=0.014$, stances, but not in the Open/Firm stance, $t_{531}=1.72, p=0.09$ (Table 2).

There were no significant differences in Sway Index scores between those with and without a history of concussion for any of the stances. When self-reported history of concussion was included in the sex differences analyses, the pattern of results remained the same: only the Open/Soft stance was significant, $F_{2,506}=3.73, p=0.025$. When selfreported history of concussion was included in the contact 
Table 2: Sway Index Values ( \pm Standard Deviation) by Stance

\begin{tabular}{|c|c|c|c|c|}
\hline & $\begin{array}{l}\text { Open Eyes/ } \\
\text { Firm Surface }\end{array}$ & $\begin{array}{l}\text { Closed Eyes/ } \\
\text { Firm Surface }\end{array}$ & $\begin{array}{l}\text { Open Eyes/ } \\
\text { Soft Surface }\end{array}$ & $\begin{array}{l}\text { Closed Eyes/ } \\
\text { Soft Surface }\end{array}$ \\
\hline Biodex sample* & $0.32 \pm 0.40$ & $0.67 \pm 0.35$ & $0.60 \pm 0.33$ & $2.08 \pm 0.26$ \\
\hline Current sample & $0.43 \pm 0.16$ & $0.62 \pm 0.23$ & $0.74 \pm 0.23$ & $1.95 \pm 0.47$ \\
\hline Sample comparison ${ }^{\dagger}$ & $d=0.35(\mathrm{~S})$ & $d=0.17$ & $d=0.51(\mathrm{M})$ & $d=0.33(\mathrm{~S})$ \\
\hline \multicolumn{5}{|l|}{ Current Sample by sex } \\
\hline Male & $0.44 \pm 0.16$ & $0.63 \pm 0.22$ & $0.77 \pm 0.25^{\ddagger}$ & $1.99 \pm 0.48$ \\
\hline Female & $0.41 \pm 0.16$ & $0.60 \pm 0.23$ & $0.72 \pm 0.20$ & $1.91 \pm 0.46$ \\
\hline \multicolumn{5}{|c|}{ Current sample by sport contact risk category } \\
\hline Low contact & $0.41 \pm 0.16$ & $0.60 \pm 0.22^{\S}$ & $0.72 \pm 0.22^{\S}$ & $1.90 \pm 0.46^{\S}$ \\
\hline High contact & $0.44 \pm 0.16$ & $0.64 \pm 0.23$ & $0.77 \pm 0.23$ & $2.00 \pm 0.47$ \\
\hline
\end{tabular}

* Data are for 17-23 year old male and female NCAA athletes $(\mathrm{n}=480)$ published by the manufacturer of the force plate technology used in this study and publicly available on the manufacturer's website. ${ }^{11}$

$\dagger$ Samples were compared using Cohen's $d$ measure of effect size ( $\mathrm{S}=$ small; $\mathrm{M}=$ medium).

$\ddagger$ Males vs. Females, $p<.05$

$\S$ Low vs. High Contact Risk Sports, $p<.05$
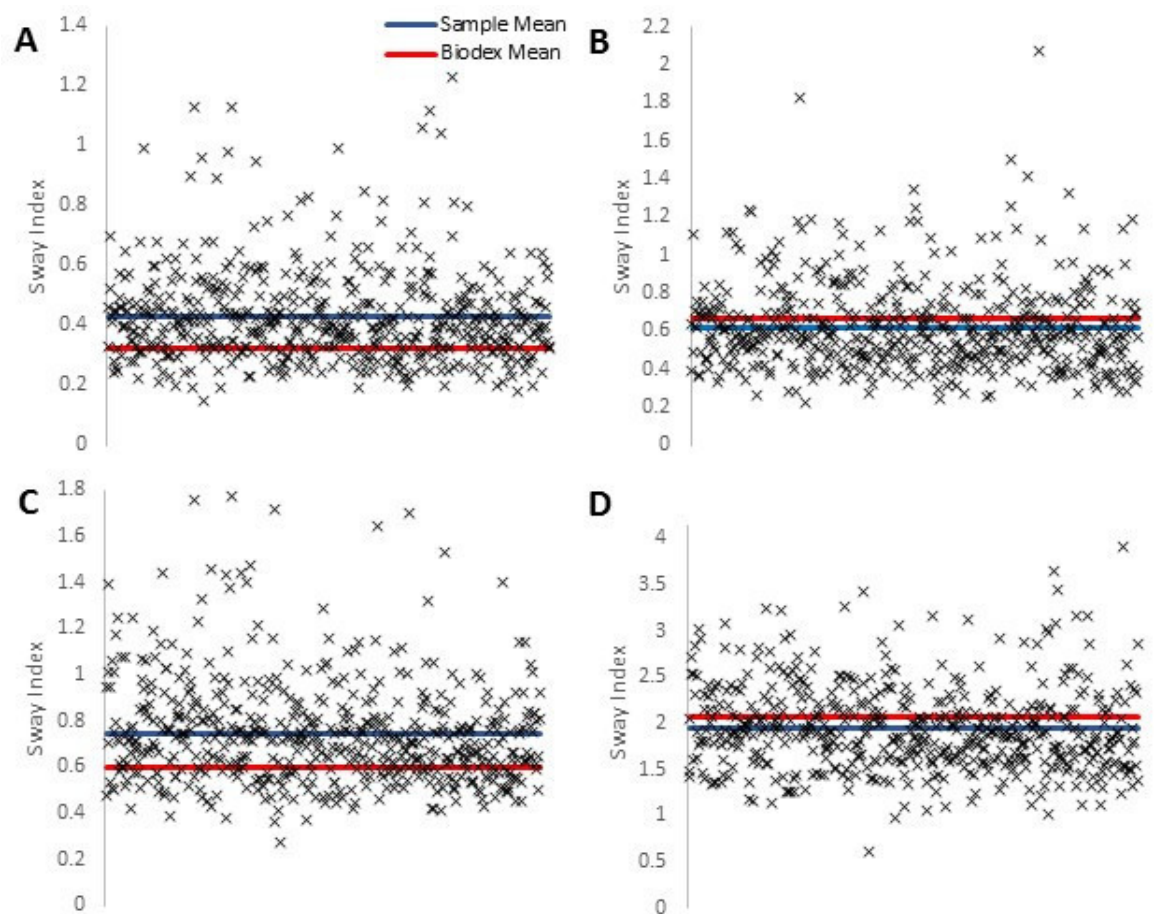

\section{Figure 1: Scatterplot of Individual Sway Index Scores of 533 Division I athletes.}

(A) Sway Index scores during the Open Eyes/Firm Surface stance. (B) Sway Index scores during the Closed Eyes/Firm Surface stance. (C) Sway Index scores during the Open Eyes/Soft Surface stance. (D) Sway Index scores during the Closed Eyes/Soft Surface stance. The solid lines represent the present sample (blue) and previously published Biodex sample (red) averages. Each $\mathrm{x}$ represents one individual. For visualization, individual data are dispersed on the $\mathrm{x}$-axis by randomly assigning each Sway Index a value from 1-533.

risk analyses, the pattern of results was very similar: significant differences were observed in the Closed/Firm, $F_{2,506}=$ $3.34, p=0.036$ and Open/Soft, $F_{2,506}=3.64, p=0.027$; the Closed/Soft stance, $F_{2,506}=2.65, p=0.072$, just missed the significance cutoff.

Since there was a significant difference in contact risk by sex $\left(\chi^{2}=34.66, p<.001\right)$, data were then analyzed separately for men and women. As shown in Figure 2, male athletes in low contact risk sports $(n=91)$ differed signifi- cantly from males in high contact risk sports $(n=200)$ in the Closed/Firm, $t_{289}=2.54, p=0.012$, Open/Soft, $t_{289}=2.21, p$ $=0.028$, and Closed/Soft, $t_{289}=2.24, p=0.026$, stances, but not in the Open/Firm stance, $t_{289}=0.58, p=0.561$. There were no significant differences in any of the stances among female athletes in low $(n=137)$ versus high $(n=105)$ contact risk groups. 

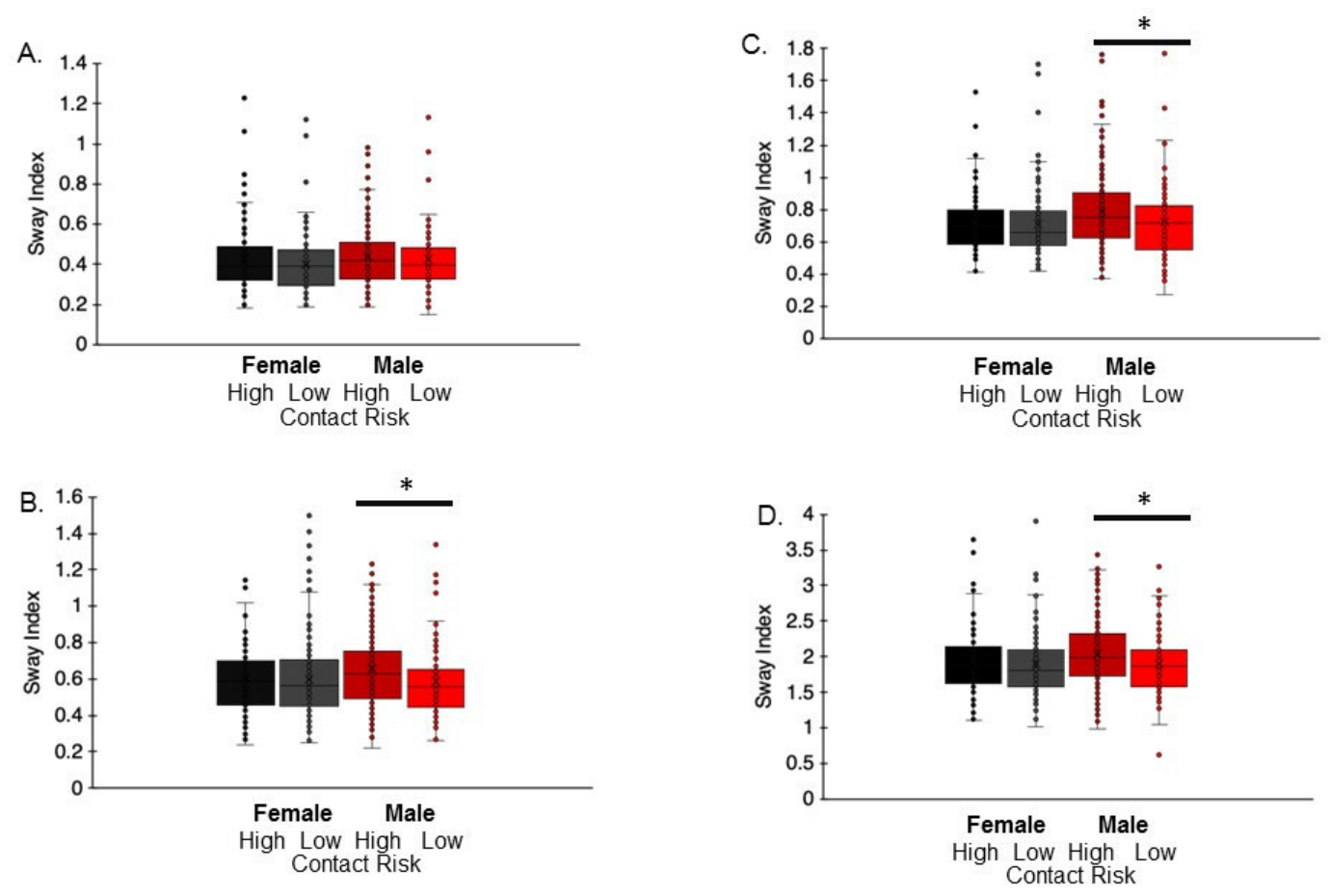

Figure 2: Sway Index scores of the Current Sample by sex and contact risk type.

(A) Sway Index scores during the Open Eyes/Firm Surface stance. (B) Sway Index scores during the Closed Eyes/Firm Surface stance. (C) Sway Index scores during the Open Eyes/Soft Surface stance. (D) Sway Index scores during the Closed Eyes/Soft Surface stance. Significant differences ( $p<.05)$ in three stances between high and low contact risk groups were observed in males only.

\section{DISCUSSION}

This study characterized balance in a large sample of uninjured NCAA Division I collegiate student-athletes using force plate technology and the mCTSIB. Participants completed the MCTSIB stances without difficulty. Assessments took less than five minutes per person, including set up and explanation, and thus were easily integrated into mandatory pre-participation screening (even when done en masse). Because force plate measurements are objective and require only limited training and technological ability, assessments can be administered by medical support staff as well as by medical and research trainees. Considering the identification of multiple factors that influence baseline postural control and the substantial variability in the present sample, the collection of individual baseline balance data is strongly recommended, whenever possible. When individual baseline data are not available, clinicians should interpret results of post-injury tests with care.

Sample averages were calculated for each of the four mCTSIB stances and compared to sample averages provided by Biodex in their manual. ${ }^{11}$ The observed small and medium effect size differences in three of the four stances was unexpected because both samples are large and comparably sized, and both consisted of ostensibly similar young healthy NCAA Division I athletes. The basis of these differences is unclear, but demographic (e.g., sex), athletic (e.g., sport), and college status (i.e., incoming versus current students) factors may have contributed. The university from which the present study was recruited, for example, has more contact/collision sports and fewer non-contact sports for men than the university from which the previously pub- lished Biodex sample was recruited. The present sample included women's crew (non-contact), field hockey (contact), and gymnastics (contact), which do not appear to have been included in the Biodex sample.

Interestingly, the present sample had substantially lower standard deviations than the prior sample (i.e., present sample's standard deviation in open eyes/firm surface stance was $40 \%$ of that of the Biodex sample), except in the most difficult stance during which participants stood on a foam surface with their eyes closed (Table 1). In this latter case, the present sample's standard deviation was $\sim 180 \%$ of that of the Biodex sample. Considering the degree of variability observed when individual Sway Index scores in the present sample were graphically displayed (Figure 1), further research is needed to characterize factors that affect collegiate athlete pre-injury balance, particularly as measured by mCTSIB and force plate technology.

Past research reports mixed findings regarding sex differences in baseline balance that may be dependent on age, ${ }^{12}$ sport type, ${ }^{13-15}$ assessment strategy (e.g., error monitoring, force plate sway), ${ }^{13}$ and stance difficulty. ${ }^{12,15}$ In studies using force plate technology, female athletes performed better on single leg, double leg, and tandem stance conditions. ${ }^{13}$ Female athletes in the present study showed modestly better balance performance in the open eyes, soft surface stance; performance in the closed eyes, soft surface stance just missed significance. Other reports of sex differences in balance have suggested that females have superior coordination of visual and proprioceptive systems, greater anatomical stability due to leaner body structures and wider pelvises, ${ }^{21}$ and physiological (central nervous system differences integrating proprioceptive input) and/or psycho- 
logical (motivation and concentration) differences. $13,22,23$ Conversely, sport-specific training and skills, such as are required for gymnastics, may also drive these differences. These sex differences by soft versus firm conditions warrant further research that considers the contributions of proprioceptive and visual systems to balance in the soft stance condition. Additionally, these differences suggest a potential need for sex-specific normative averages to more fully inform clinical interpretation of an individual's Sway scores following injury.

Past work has also demonstrated differences in baseline balance performance in athletes participating in different sports. ${ }^{15}$ The present study, however, is among the first to show that participation in high contact sports may also be associated with reductions in postural control during baseline assessments. Specifically, the low contact risk group, comprised of athletes who participate in sports with minimal or no contact, showed better balance than the high contact risk group in the more challenging Open/Soft, Closed/ Firm, and Closed/Soft stances. When males and females were analyzed separately, results indicated that these differences were driven exclusively by the male athletes; no significant differences by sport contact risk were observed for the female athletes. Subconcussive impacts, sport-specific strength and conditioning regimens, or years of participation are potential explanations, ${ }^{24}$ but future research specifically addressing these factors is needed before conclusions can be drawn. As with sex-specific normative averages, sport-specific averages may improve clinical interpretation of post-injury balance disturbances.

These results should be considered in light of some limitations. The data were collected from a sample of collegiate athletes at one university; thus, the findings may not generalize to all collegiate athletes. Only NCAA Division I athletes were tested; future studies should include athletes from other NCAA divisions and sports. Nearly all participants were tested on a limited number of days in the summer prior to their arrival on campus and most were incoming first year students. Balance may improve with training, during the intensive competitive season, and from overall exposure to the collegiate athletics environment; thus, means and/or SDs may be lower in more experienced college athletes. Future studies would benefit from further assessment of concussion history, including number of prior concussions and recency of concussive symptoms.

A critical observation of this study was the substantial variability in baseline balance performance in every stance, even among this sample of ostensibly healthy, uninjured NCAA Division I athletes across a narrow age range (18-23 years). This may suggest a large range of 'normal' balance function in non-injured collegiate athletes. It also suggests that factors such as years of collegiate sport participation, subconcussive impact exposure, testing time (e.g., during intensive training periods, during the competitive season), and proximal health factors (e.g., fatigue, recent exercise, past lower body injuries) $)^{25,26}$ can alter balance through their influence on motor control, responses to proprioceptive and visual cues, coordination, strength, and range of motion. This study cannot address these specific causal factors, but the large distribution of individual values around the mean suggests such studies are needed, particularly for supporting clinical interpretation of changes in balance from pre- to post-injury.

\section{CONCLUSION}

The present results suggest that changes in balance from pre- to post-injury may be clinically interpreted differently for individuals with substantially below average sway (i.e., superior balance) versus those at or above the average. For example, an individual's post-injury Sway score of 0.64 during the Open Eyes/Soft Surface stance may not be seen as a clinically significant impairment if the current sample's (or the Biodex sample's) baseline averages are used as proxies for pre-injury balance. However, if that individual had a baseline Sway Index score of 0.39 (1 standard deviation below the group average), a 0.64 represents a $60 \%$ increase in sway from baseline, which may, in fact, be clinically meaningful. Much research remains needed in this area, but these results suggest that physical therapists and other clinicians should be cautious of the risk for over- or underdiagnosing balance disturbances when referencing published sample averages during patient examination. The results also support the need for additional studies in this domain to build a comprehensive database from which accurate normative averages may be developed.

\section{ACKNOWLEDGMENTS}

The authors thank the staff of the Rutgers Department of Sports Medicine for their assistance with this study and thank Anthony Bocchine for assistance with figure preparation. This study was supported, in part, by a grant (NJCBIR13IRG028) from the NJ Commission on Brain Injury Research (Trenton, NJ) and a grant (K02 AA025123) from the National Institutes of Health to JFB. The grantors had no involvement in the development, execution, or analyses of this study.

\section{CONFLICT OF INTEREST STATEMENT}

All authors report no conflict of interest.

Submitted: November 09, 2019 CDT, Accepted: July 24, 2020

CDT 


\section{REFERENCES}

1. Zuckerman SL, Kerr ZY, Yengo-Kahn A, Wasserman E, Covassin T, Solomon GS. Epidemiology of sportsrelated concussion in NCAA athletes from 2009-2010 to 2013-2014. Am J Sports Med. 2015;43(11):2654-2662. doi:10.1177/03635465155996 $\underline{34}$

2. McCrory P, Meeuwisse W, Dvorak J, et al. Consensus statement on concussion in sport-the 5 th international conference on concussion in sport held in Berlin, October 2016. Br J Sports Med. 2017;51(11):838-847.

3. Broglio SP, Macciocchi SN, Ferrara MS. Sensitivity of the concussion assessment battery. Neurosurgery. 2007;60(6):1050-1057; discussion 1057-1058. doi:10.1 227/01.neu.0000255479.90999.c0

4. Broglio SP, Cantu RC, Gioia GA, et al. National Athletic Trainers' Association position statement: Management of sport concussion. J Athl Train. 2014;49(2):245-265. doi:10.4085/1062-6050-49.1.07

5. Mrazik M, Ferrara MS, Peterson CL, et al. Injury severity and neuropsychological and balance outcomes of four college athletes. Brain Injury. 2000;14(10):921-931. doi:10.1080/026990500445736

6. Peterson CL, Ferrara MS, Mrazik M, Piland S, Elliott R. Evaluation of neuropsychological domain scores and postural stability following cerebral concussion in sports. Clin J Sport Med. 2003;13(4):230-237. doi:1 0.1097/00042752-200307000-00006

7. Riemann BL, Guskiewicz KM. Effects of mild head injury on postural stability as measured through clinical balance testing. J Athl Train.

2000;35(1):19-25.

8. Guskiewicz KM. Balance assessment in the management of sport-related concussion. Clin Sport Med. 2011;30(1):89-102. doi:10.1016/j.csm.2010.09.0 $\underline{04}$

9. Shumway-Cook A, Horak FB. Assessing the influence of sensory interaction of balance. Suggestion from the field. Phys Ther. 1986;66(10):1548-1550.

10. Cohen H, Blatchly CA, Gombash LL. A study of the clinical test of sensory interaction and balance. Phys Ther. 1993;73(6):346-351; discussion 351-344. doi:1 $\underline{0.1093 / \mathrm{ptj} / 73.6 .346}$

11. Biodex Medical Systems I. Addendum balance system SD and BioSway. 2016. http://www.biodex.co m/sites/default/files/950440man_add_14074revb.pdf.
12. Paniccia M, Wilson KE, Hunt A, et al. Postural stability in healthy child and youth athletes: The effect of age, sex, and concussion-related factors on performance. Sports Health. 2018;10(2):175-182. doi:1 $\underline{0.1177 / 1941738117741651}$

13. Howell DR, Hanson E, Sugimoto D, Stracciolini A, Meehan WPI. Assessment of the postural stability of female and male athletes. Clin J Sport Med. 2017;27(5):444-449. doi:10.1097/jsm.0000000000000 $\underline{374}$

14. Burk JM, Munkasy BA, Joyner AB, Buckley TA. Balance error scoring system performance changes after a competitive athletic season. Clin J Sport Med. 2013;23(4):312-317. doi:10.1097/jsm.0b013e31828563 $\underline{3 f}$

15. Zimmer A, Piecora K, Schuster D, Webbe F. Sport and team differences on baseline measures of sportrelated concussion. J Athl Train. 2013;48(5):659-667. $\underline{\mathrm{d}}$ oi:10.4085/1062-6050-48.5.06

16. Olson RL, Brush CJ, Ehmann PJ, Buckman JF, Alderman BL. A history of sport-related concussion is associated with sustained deficits in conflict and error monitoring. Int J Psychophysiol. 2018;132(Pt A):145-154. doi:10.1016/j.ijpsycho.2018.01.006

17. Sosnoff JJ, Broglio SP, Shin S, Ferrara MS. Previous mild traumatic brain injury and postural-control dynamics. J Athl Train. 2011;46(1):85-91. doi:10.4085/ 1062-6050-46.1.85

18. Guskiewicz KM, Perrin DH. Research and clinical applications of assessing balance. J Sport Rehabil. 1996;5(1):45-63. doi:10.1123/jsr.5.1.45

19. Rice SG. Medical conditions affecting sports participation. Pediatrics. 2008;121(4):841-848. doi:1 0.1542/peds.2008-0080

20. Cohen J. Statistical Power Analysis for the Behavioral Sciences. 2nd ed. Hillsdale, NJ: Lawrence Erlbaum Associates; 1988.

21. Hrysomallis C. Balance ability and athletic performance. Sports Med. 2011;41(3):221-232. doi:1 0.2165/11538560-000000000-00000

22. Steindl R, Kunz K, Schrott-Fischer A, Scholtz AW. Effect of age and sex on maturation of sensory systems and balance control. Dev Med Child Neurol. 2006;48(6):477-482. doi:10.1017/s0012162206001022 
23. Lockman JJ, Thelen E. Developmental biodynamics: Brain, body, behavior connections. Child Dev. 1993;64(4):953-959. doi:10.1111/i.1467-86 24.1993.tb04181.x

24. Gysland SM, Mihalik JP, Register-Mihalik JK, Trulock SC, Shields EW, Guskiewicz KM. The relationship between subconcussive impacts and concussion history on clinical measures of neurologic function in collegiate football players. Ann Biomed Eng. 2012;40(1):14-22. doi:10.1007/s10439-011-042 $\underline{1-3}$
25. McKeon PO, Hertel J. Systematic review of postural control and lateral ankle instability, part I: Can deficits be detected with instrumented testing. J Athl Train. 2008;43(3):293-304. doi:10.4085/1062-605 $\underline{0-43.3 .293}$

26. Paillard T. Effects of general and local fatigue on postural control: A review. Neurosci Biobehav Rev. 2012;36(1):162-176. doi:10.1016/i.neubiorev.2011.0 $\underline{5.009}$ 